\title{
Decreased expression of the augmenter of liver regeneration results in growth inhibition and increased chemosensitivity of acute $T$ lymphoblastic leukemia cells
}

\author{
YAN SHEN ${ }^{1}$, QI LIU ${ }^{2}$, SHIFENG LOU ${ }^{1}$, YUN LUO ${ }^{1}$, HANG SUN $^{2}$, HANQING ZENG ${ }^{1}$ and JIANCHUAN DENG ${ }^{1}$ \\ ${ }^{1}$ Department of Hematology and ${ }^{2}$ Institute for Viral Hepatitis, Key Laboratory of Molecular Biology for Infectious \\ Diseases, The Second Affiliated Hospital, Chongqing Medical University, Chongqing 400010, P.R. China
}

Received March 23, 2017; Accepted August 17, 2017

DOI: $10.3892 /$ or.2017.5984

\begin{abstract}
Augmenter of liver regeneration (ALR) plays crucial roles in cell survival and growth. Previous studies have demonstrated that ALR exerts a protective effect on toxic agent-induced cell death in acute $\mathrm{T}$ lymphoblastic leukemia cells and ALR knockdown can sensitize cancer cells to radiation. However, the biological functions of ALR against drug resistance in T-cell acute lymphoblastic leukemia are mostly unknown. In the present study, we investigated the effect of small interfering RNA (siRNA)-induced ALR silencing on cell proliferation and sensitivity to vincristine (VCR) of Jurkat cells. We found that ALR siRNA effectively decreased the ALR expression, then inhibited cell growth and increased sensitivity to VCR in Jurkat cells. Flow cytometry assay revealed that the downregulation of ALR expression promoted cell apoptosis and regulated cell cycle distribution. Following incubation with VCR, apoptosis-related proteins, such as pro-PARP, pro-caspase 8 , pro-caspase 3 and $\mathrm{Bcl}-2$ were downregulated in the siRNA/ALR group. Pretreatment with siRNA/ALR in combination with VCR resulted in prolonged G2/M arrest, accompanied by downregulation of cdc25c and cdc2 expression and dissociation of cyclin B1. In conclusion, the results of this study demonstrated that targeted inhibition of the ALR expression in Jurkat cells triggered cell growth inhibition and sensitized cells to VCR via promoting apoptosis and regulating the cell cycle.
\end{abstract}

\section{Introduction}

It is known that T-cell acute lymphoblastic leukemia (T-ALL) is an invasive hematological malignancy derived from normal

Correspondence to: Professor Jianchuan Deng, Department of Hematology, The Second Affiliated Hospital, Chongqing Medical University, 76 Linjiang Road, Chongqing 400010, P.R. China E-mail: dengjecq@163.com

Key words: T-cell acute lymphoblastic leukemia, augmenter of liver regeneration, siRNA, drug sensitivity immature T cells, causing accumulation of leukemia cells in the bone marrow and suppression of normal hematopoiesis. T-ALL accounts for $\sim 15 \%$ of pediatric and $25 \%$ of adult ALL cases (1). Intensive combination chemotherapy has improved the prognosis of patients with acute leukemia, however the outcome of patients who fail to respond to conventional chemotherapy is usually poor and the mortality rate is $\sim 20 \%$ in children and up to $50 \%$ in adults with T-ALL (2-4). The emergence of resistance to chemotherapy is one of the main causes of treatment failure in acute leukemia $(5,6)$. Therefore, the development of effective, new therapeutic methods, such as molecular-targeted therapy and enhancement of sensitivity to chemotherapy, in order to overcome drug resistance in leukemia cells may potentially improve the effects of chemotherapy $(4,5)$.

Apoptosis, the natural process of programmed cell death, is essential for maintaining homeostasis $(7,8)$. Apoptosis defects results in resistance to chemotherapeutic medicines (9-11). As cytotoxic agents exert their anticancer effects by inducing apoptosis, new approaches for antitumor treatment have focused on targeting mediators of the apoptosis pathways (12-14).

As a flavin-dependent sulfhydryl oxidase, augmenter of liver regeneration (ALR) is encoded by the growth factor ervl-like (GFER) gene (15). ALR is expressed in a variety of organs and tissues, such as hepatocellular carcinoma (16), tubular epithelial cells (17), human-derived glioma cells (18) and muscle tissue (19), and plays a central role in the synthesis of hepatocyte DNA, immune adjustment, cell cycle regulation and anti-apoptosis (20-24). Our previous studies revealed that exogenous ALR protected acute lymphocytic leukemia cells from vincristine (VCR)-induced cell death, via decreasing activated caspase 8 , increasing the ratio of $\mathrm{Bcl}-2 / \mathrm{Bax}$, reducing apoptotic cells and attenuating $\mathrm{G} 2 / \mathrm{M}$ arrest (25). It has been reported that downregulation of ALR expression through antisense oligonucleotides and small interfering RNA (siRNA) led to cell proliferation inhibition and increased the sensitivity of cancer cells to radiation $(18,26,27)$. To date, there are few studies on whether the suppression of ALR expression by siRNA could sensitize T-ALL cells to chemotherapeutic agents.

In the present study, we investigated the effect of siRNA-induced ALR silencing on apoptosis and cell cycle distribution and evaluated whether the suppression of ALR 
could sensitize the human T-ALL cell line Jurkat to the antileukemic agent VCR.

\section{Materials and methods}

Cell culture. Jurkat T leukemia cells (Nanjing KeyGen Biotech, Nanjing, China) were maintained in suspension in RPMI-1640 medium (HyClone, Logan, UT, USA) supplemented with $10 \%$ fetal bovine serum (FBS; HyClone), $100 \mathrm{U} / \mathrm{ml}$ penicillin and streptomycin. The cells were grown at $37^{\circ} \mathrm{C}$ in a humidified atmosphere with $5 \% \mathrm{CO}_{2}$.

RNA interference. The target sequence for ALR was 5'-GTGTGCTGAAGACCTAAGA-3'. Sense siRNA was 5'-GAGTGTGCTGAAGACCTAAGA-3' and antisense siRNA was 5'-TCTTAGGTCTTCAGCACACTC-3'. Then, the siRNA was cloned into a CMV promoter-driven lentiviral expression vector GV118 (GeneChem, Shanghai, China). The GV118-mock vector was set as a negative control. For infection $5.5 \times 10^{4}$ Jurkat cells were collected and resuspended in $1 \mathrm{ml}$ complete RPMI-1640 medium. The cells were infected with GV118 or GV118-mock at a multiplicity of infection (MOI) of 1. Twenty-four hours after the infection, the medium was replaced with $1 \mathrm{ml}$ of fresh culture medium. Then the cells were grown for another $48 \mathrm{~h}$ and fluorescence microscopy analysis of the GFP expression was performed. The expression of ALR mRNA was further confirmed by fluorescence quantitative polymerase chain reaction (FQ-PCR) and the ALR protein was determined by western blotting and confocal laser scanning microscope.

Real-time reverse transcription PCR. Total RNA was extracted from Jurkat cells using the RNeasy Micro kit (Nanjing KeyGen Biotech, Nanjing, China) according to the manufacturer's instructions. Total RNA $(1 \mu \mathrm{g})$ from each sample was used to generate first-strand cDNA synthesis using PrimeScript RT reagent kit (Takara Biotechnology, Dalian, China). Reverse transcription reaction started at $37^{\circ} \mathrm{C}$ for $15 \mathrm{~min}$, followed by $5 \mathrm{sec}$ at $85^{\circ} \mathrm{C}$. Real-time PCR was conducted using the SYBR Premix Ex Taq ${ }^{\mathrm{TM}}$ II kit (Takara) according to the manufacturer's instructions. cDNA product $(1 \mu \mathrm{l})$ was used for the real-time PCR in a final volume of $25 \mu \mathrm{l}$ containing $12.5 \mu \mathrm{l}$ of 2X SYBR Premix Ex Taq ${ }^{\mathrm{TM}}$ II and $0.75 \mu \mathrm{l}$ of the forward and reverse primers (Table I). The thermal cycling conditions were as follows: initial denaturation step at $95^{\circ} \mathrm{C}$ for $1 \mathrm{~min}$, followed by 40 cycles of denaturation for $10 \mathrm{sec}$ at $95^{\circ} \mathrm{C}$ and annealing for $30 \mathrm{sec}$ at $60^{\circ} \mathrm{C}$. The CFX96 Manager software (Bio-Rad, Hercules, CA, USA) was used to calculate the relative concentrations of the PCR products. All the samples were tested in triplicate and the data were analyzed using the $2^{-\Delta \Delta \mathrm{Ct}}$ method.

Western blotting. Briefly, Jurkat cells were collected and then washed twice with PBS. RIPA $(500 \mu 1)$ was added to the cell pellet to extract the total protein of the cells. Protein samples were resolved on $12 \%$ SDS-polyacrylamide gels and electroblotted onto polyvinylidene difluoride (PVDF) membranes. The membranes were blocked in a Tris-buffered saline/Tween-20 (TBST) solution containing 2\% nonfat dry milk at room temperature for $1 \mathrm{~h}$ and subsequently incubated with the respective primary antibodies (Epitomics, Burlingame,
Table I. Primers of human ALR and $\beta$-actin.

\begin{tabular}{ll}
\hline Target gene & \multicolumn{1}{c}{ Primer sequence } \\
\hline ALR & F: $\left(5^{\prime}-3^{\prime}\right)$ AAGGTGAGGCTGGGAATTT \\
& R: $\left(5^{\prime}-3^{\prime}\right)$ GTCTTCATGTCGCGCTTCT \\
$\beta$-actin & F: $\left(5^{\prime}-3^{\prime}\right)$ TCAGGTCATCACTATCGGCAAT \\
& R: $\left(5^{\prime}-3^{\prime}\right)$ AAAGAAAGGGTGTAAAACGCA
\end{tabular}

ALR, augmenter of liver regeneration; F, forward; R, reverse.

CA, USA) diluted in PBS for $2 \mathrm{~h}$ at room temperature. Following washing with TBST for three times, the membranes were incubated with HRP-conjugated secondary antibodies. The expression of GAPHD was used as an internal loading control. Immunoblot quantification was carried out by densitometry using Image Lab statistical software (Bio-Rad Laboratories, Inc., Hercules, CA, USA).

Cell proliferation assay. To investigate the effects of ALR silencing on Jurkat leukemia cell growth and sensitivity to VCR, cells were seeded at $1 \times 10^{5} /$ well in 96-well microtiter plates. After culturing for 1,2,3 and 4 days, the quantity of viable cells was detected. Afterwards, $20 \mu \mathrm{l}$ of MTS solution was added into each well and the cells were incubated for $3 \mathrm{~h}$. Complete solubilization of the dye was achieved by vortexing the plate, and then absorbance was read at $490 \mathrm{~nm}$ using SpectraMax M2 plate reader. Wells containing medium but no cells, served as blank controls. Meanwhile, after $48 \mathrm{~h}$ of infection, cells were incubated with various concentrations of VCR $(0.0625-10 \mu \mathrm{g} / \mathrm{ml})$ for another $24 \mathrm{~h}$ at $37^{\circ} \mathrm{C}$. The viable cell count in each well was assessed by the $\mathrm{OD}$ value. The percentage of surviving cells was calculated and the $\mathrm{IC}_{50}$ value was determined by nonlinear regression analysis using SPSS 17.0 software (SPSS, Inc., Chicago, IL, USA).

Cell cycle analysis. After $72 \mathrm{~h}$ of infection, cell samples were harvested and washed once in cold PBS, then fixed and stained with PI solution. The cell cycle was detected using the cellular DNA flow cytometric analysis kit (Nanjing KeyGen Biotech) according to the manufacturer's protocol. The percentages of cells within the G1/G0, S and G2/M phases were determined by flow cytometry. The results were analyzed using CellQuest software (BD Biosciences, San Jose, CA, USA). For the chemotherapeutic drug tests, after $48 \mathrm{~h}$ of infection, the cells were cultured with VCR $1 \mu \mathrm{g} / \mathrm{ml}$ for an additional $24 \mathrm{~h}$ and then analyzed as aforementioned.

Analysis of apoptosis. Apoptosis was assessed using the Annexin-V-PE/7-AAD Apoptosis Detection kit (Nanjing KeyGen Biotech). After $48 \mathrm{~h}$ of infection, the cells were incubated with $1 \mu \mathrm{g} / \mathrm{ml} \mathrm{VCR}$ or alone, for an additional $24 \mathrm{~h}$. Then cell samples were collected and washed twice with cold PBS. Subsequently, the cells were stained with $1 \mu \mathrm{l}$ Annexin V-PE and $5 \mu 17$-AAD. Flow cytometric analysis was performed on a FACScan flow cytometer (BD Biosciences). Results were analyzed using CellQuest PRO software (BD Biosciences). 
A

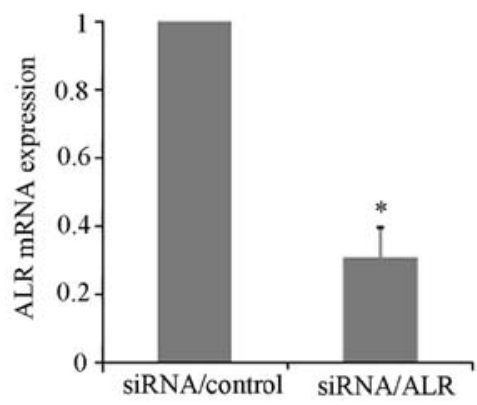

B

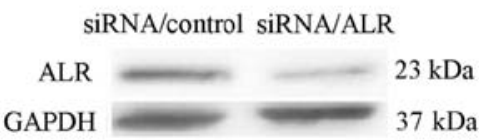

$\mathrm{C}$

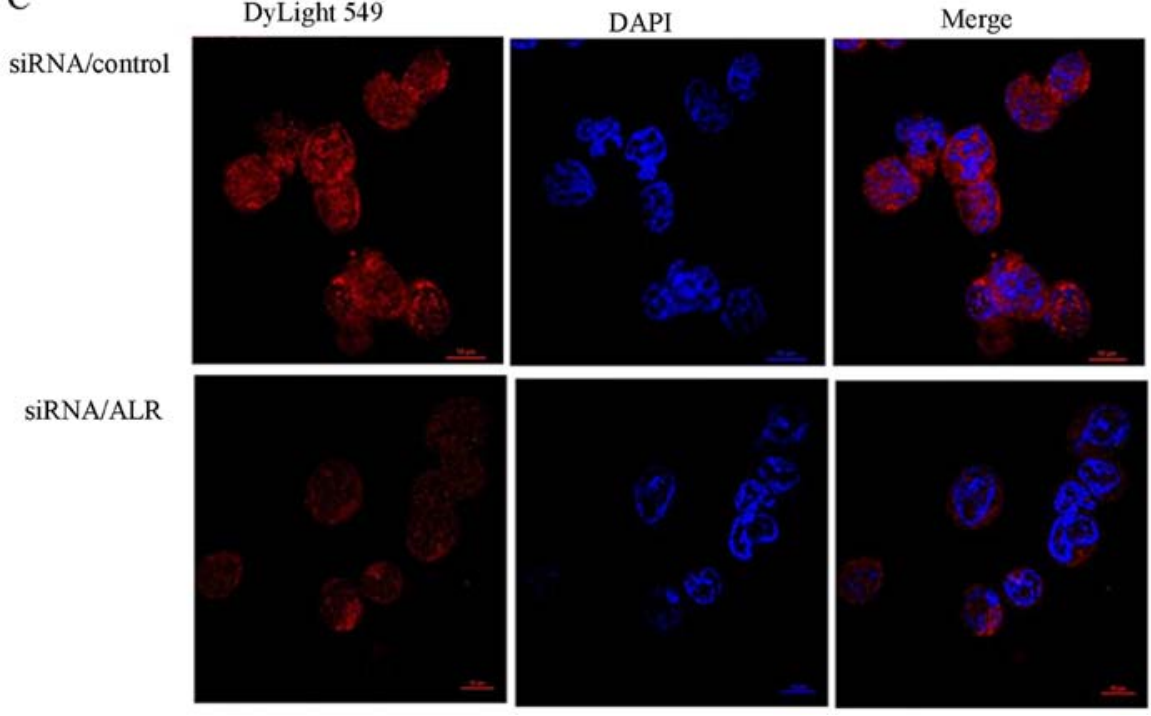

Figure 1. ALR expression in ALR siRNA-infected group and control group. Data represent the mean \pm SEM from three independent experiments (A) ALR mRNA expression was detected by real-time PCR ( ${ }^{*} \mathrm{p}=0.0003, \mathrm{n}=3$ ). (B) The protein levels of ALR were determined by western blot analysis. (C) The presence of ALR was revealed by confocal microscopy immunodetection. The nuclei were stained with DAPI, the specific ALR immunodetection was revealed by DyLight 549, and the 'merge' indicates colocalization. ALR, augmenter of liver regeneration.

Statistical analysis. All data are reported as the means \pm SEM. Comparisons between pairs of groups were made by Student's t-test or one way ANOVA for multiple group comparisons. A P-value $<0.05$ was considered to indicate a statistically significant difference. Statistical analysis was performed using SPSS 17.0 software (SPSS, Inc.).

\section{Results}

ALR siRNA effectively decreases ALR expression in Jurkat cells. The expression level of ALR in the T-ALL Jurkat cell line was detected by real-time PCR, western blot analysis and confocal laser scanning microscopy. ALR-specific siRNA induced a marked decrease of ALR mRNA expression in Jurkat cells (Fig. 1A). The protein level of ALR was greatly downregulated in the ALR siRNA-infected group compared with the level in the mock control group (Fig. 1B). After $72 \mathrm{~h}$ of infection, the relative expression of ALR mRNA was $28.17 \pm 2.63 \%$, while the relative expression of ALR protein was $21.45 \pm 1.98 \%$, respectively. Compared with the control group, a significant reduction of the ALR protein in the ALR siRNA-infected group was determined by confocal microscopic immunodetection (Fig. 1C).

Downregulation of ALR expression inhibits proliferation of Jurkat cells. As extraneous ALR is associated with the survival of Jurkat T leukemia cells, the effect of ALR siRNA on cell proliferation was detected. Twenty-four, 48, 72 and $96 \mathrm{~h}$ after infection with siRNA, cell growth was determined using MTS assay. The cell proliferation curve demonstrated that compared to the control group, ALR siRNA significantly reduced cell growth in a time-dependent manner (Fig. 2). At $24 \mathrm{~h}$ post-infection, the cell growth was $96.84 \pm 5.76 \%$ and rapidly dropped to $49.38 \pm 7.21 \%$ at $96 \mathrm{~h}$ in the ALR siRNA group. The results revealed that suppression of the ALR expression by siRNA significantly inhibited cell proliferation in Jurkat cells.

Downregulation of ALR expression induces apoptosis in Jurkat cells. We next investigated whether the ALR siRNA-induced proliferation suppression was related to apoptosis. The FCM analysis revealed that the apoptosis rate was $19.85 \pm 1.74 \%$ in the ALR siRNA-infected group, compared with $7.48 \pm 0.83 \%$ in the control group (Fig. 3). Western blot analysis revealed that after ALR siRNA infection, pro-PARP, pro-caspase 8, pro-caspase 3 and Bcl-2 expression were downregulated in the Jurkat cells (Fig. 4). These results revealed that the increased apoptosis induced by ALR siRNA was partially responsible for the inhibition of cell proliferation in the Jurkat cells.

Downregulation of ALR expression reduces the $G 2 / M$ ratio in Jurkat cells. It is known that cell cycle progression influences 


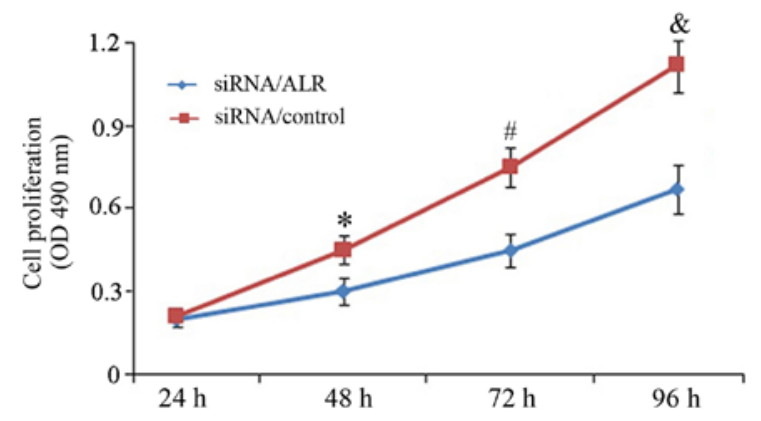

Figure 2. Effect of ALR siRNA on cell proliferation. Jurkat cells were infected with siRNA and cultured for $96 \mathrm{~h}$ and the cell growth was detected using MTS assay. Significance: ${ }^{*} \mathrm{p}=0.006,{ }^{\sharp} \mathrm{p}=0.0001$ and ${ }^{\mathrm{\&}} \mathrm{p}=0.0003$ vs. siRNA/control $(n=3)$. ALR, augmenter of liver regeneration.

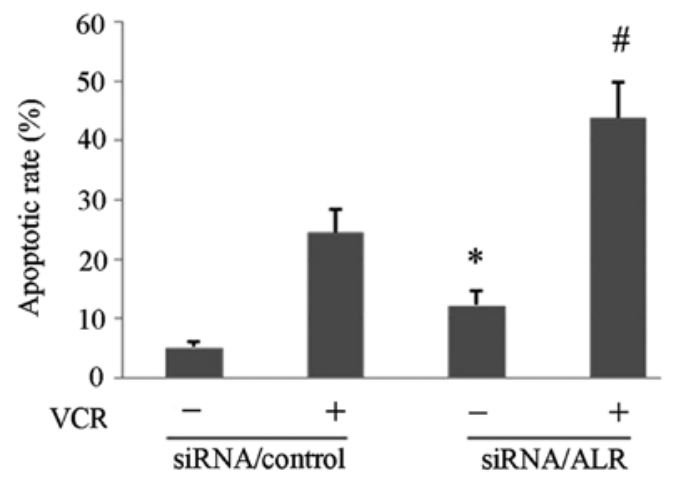

Figure 3. Suppression of the ALR expression by siRNA promotes apoptosis in Jurkat cells. After $48 \mathrm{~h}$ of infection, Jurkat cells were cultured for an additional $24 \mathrm{~h}$ alone, or with VCR. Then apoptotic cells were detected by AnnexinV/PI staining using FCM. Data represent the mean \pm SEM from three independent experiments. The average percentages of Annexin V-positive Jurkat cells from at least three independent experiments. Significance: ${ }^{*} \mathrm{p}=0.001$ vs. siRNA/control $(\mathrm{n}=3),{ }^{*} \mathrm{p}=0.003$, vs. siRNA/control + VCR $(\mathrm{n}=3)$. ALR, augmenter of liver regeneration; VCR, vincristine.

cell proliferation, thus we detected the effects of ALR siRNA infection on cell cycle distribution. Data revealed that suppression of ALR expression induced a decreased percentage of G2/M-phase cells (Fig. 5). The percentage of G0/G1-phase cells was $51 \%$, of S-phase cells was $39.23 \%$ and of G2/M-phase cells was $8.53 \%$ in typical ALR siRNA-infected cells, compared with $50.19 \%, 28.59 \%$ and $20.5 \%$ in the control cells, respectively. Then we detected the G2/M-phase regulatory factors, including cyclin B1, P53, cdc2 and cdc25c proteins, for their molecular mechanisms. Western blot analysis revealed that cyclin B1 and P53 expression was downregulated, while $\operatorname{cdc} 25 \mathrm{c}$ and $\mathrm{cdc} 2$ expression was upregulated (Fig. 4).

Downregulation of ALR expression increases sensitivity to VCR in Jurkat cells. To investigate the effect of ALR downregulation on the response of Jurkat cells to a chemotherapeutic agent, we suppressed the ALR expression by siRNA in Jurkat cells and then detected cell proliferation and apoptosis and cell cycle change induced by VCR. Data revealed that the $\mathrm{IC}_{50}$ value for VCR in the control siRNA group was $4.87 \pm 0.52 \mu \mathrm{g} / \mathrm{ml}$. Jurkat cells infected with siRNA/ALR were more sensitive and the $\mathrm{IC}_{50}$ value decreased to $1.32 \pm 0.17 \mu \mathrm{g} / \mathrm{ml}$ (Fig. 6). Subsequently, we
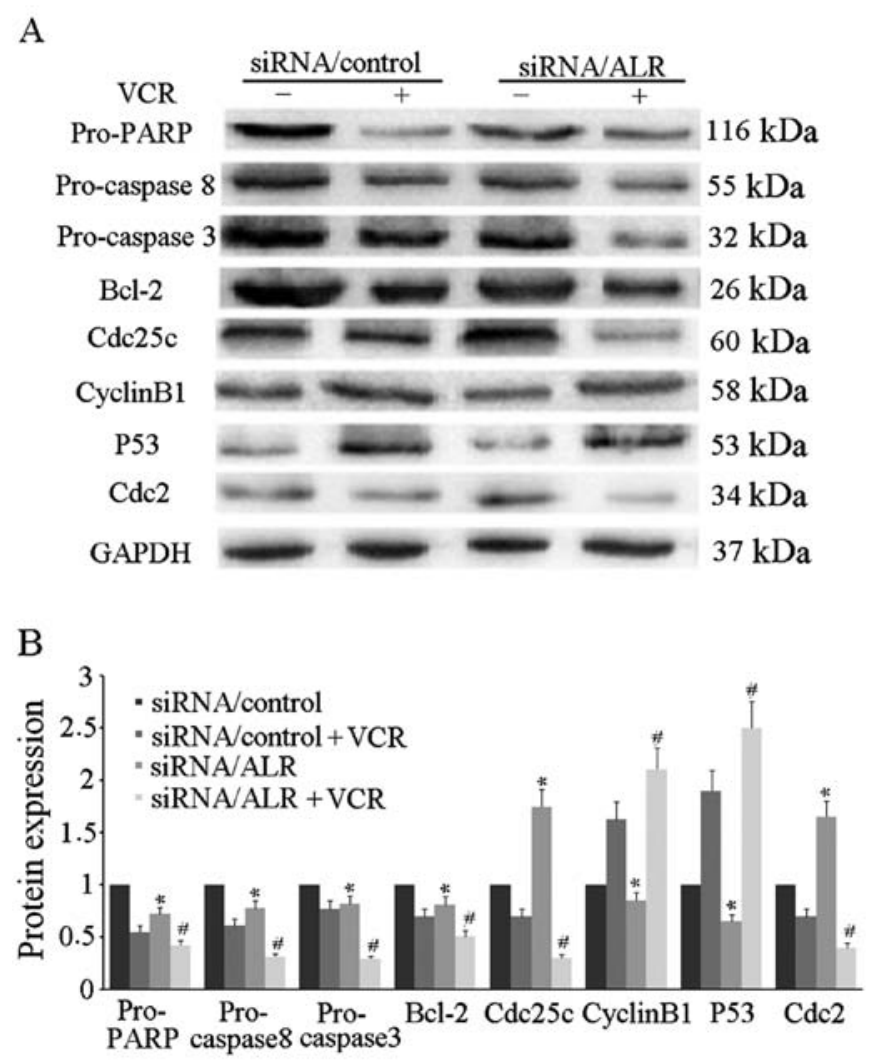

Figure 4. Effect of ALR siRNA on the expression level of apoptosis and cell cycle-related proteins. After $48 \mathrm{~h}$ of infection, Jurkat cells were incubated for an additional $24 \mathrm{~h}$ alone, or with VCR. Western blot analyses were performed to detect the protein expression. (A) Representative western blot analysis of proteins from cells transfected with siRNA. (B) The expression level of each band was measured by densitometry and normalized to the respective GAPDH. Data represent the mean \pm SEM $(n=3)$. " $p<0.05$ vs. siRNA/control, ${ }^{\#} \mathrm{p}<0.05$ vs. siRNA/control + VCR. ALR, augmenter of liver regeneration, VCR, vincristine.

examined the apoptotic rate induced by VCR after the siRNA/ALR infection. FCM analysis revealed that after the siRNA infection, VCR induced a higher apoptotic rate in the siRNA/ALR-infected group $(43.75 \pm 5.96 \%)$ than that in the control siRNA infected group $(24.59 \pm 3.76 \%)$ (Fig. 3). The western blot analysis revealed that the process of VCR-induced apoptosis in the siRNA/ALR-infected cells was accompanied by the decreased expression of the pro-PARP, pro-caspase 8 , pro-caspase 3 and Bcl-2 proteins (Fig. 4). Furthermore, cell cycle stage analysis revealed that in comparison with the control siRNA group, VCR prolonged G2/M arrest in the siRNA/ALR group (Fig. 5). Then we detected the expression of several G2/M-phase cell cycle regulatory factors to explore the molecular mechanisms. Western blot analysis revealed that the expression of cyclin B1 and P53 was increased while that of cdc25c and cdc2 was decreased (Fig. 4).

\section{Discussion}

ALR was first isolated from neonatal mouse hepatocytes in 1994 (28). ALR exhibits numerous biological activities, such as anti-apoptosis, immunoregulation, antioxidant and preserving mitochondrial function $(20-24,29)$. Our 


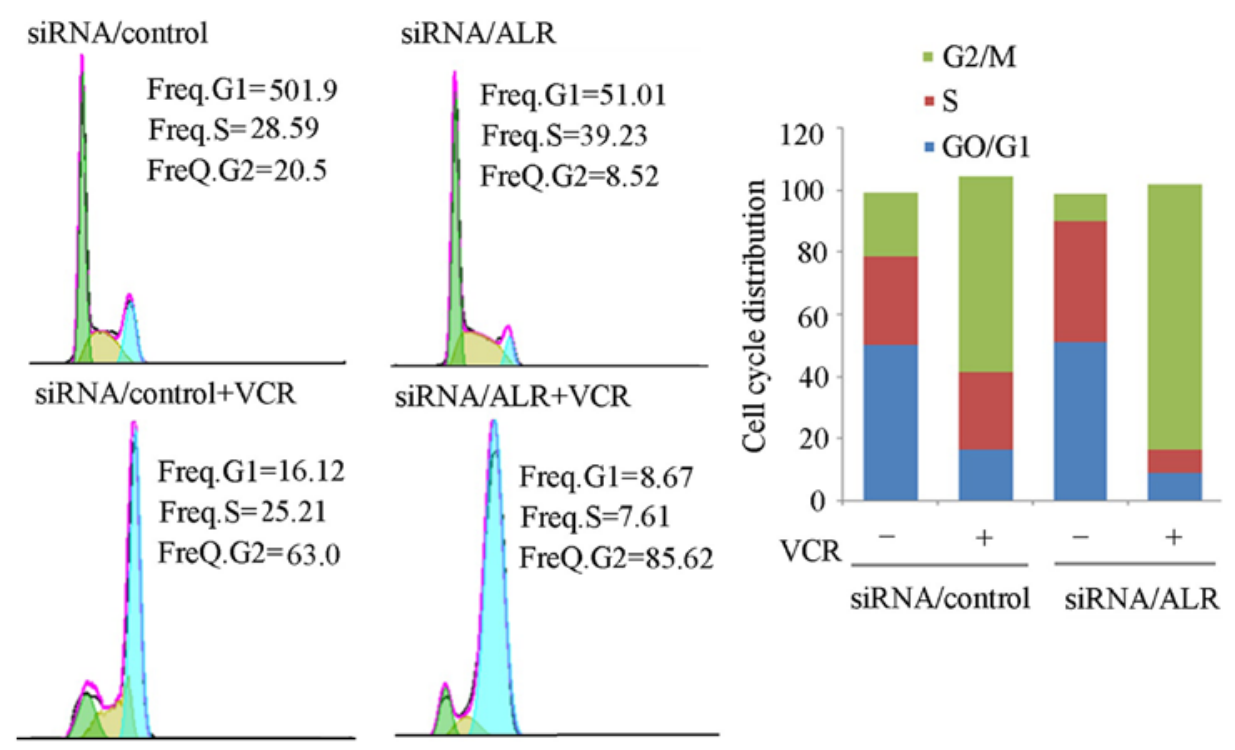

Figure 5. Suppression of ALR expression by siRNA alters cell cycle distributions in Jurkat cells. After $48 \mathrm{~h}$ of infection, Jurkat cells were incubated for an additional $24 \mathrm{~h}$ alone or with VCR and stained with PI. FCM analyses were performed to determine the cell cycle distribution using the cell cycle detection kit. ALR, augmenter of liver regeneration; VCR, vincristine.

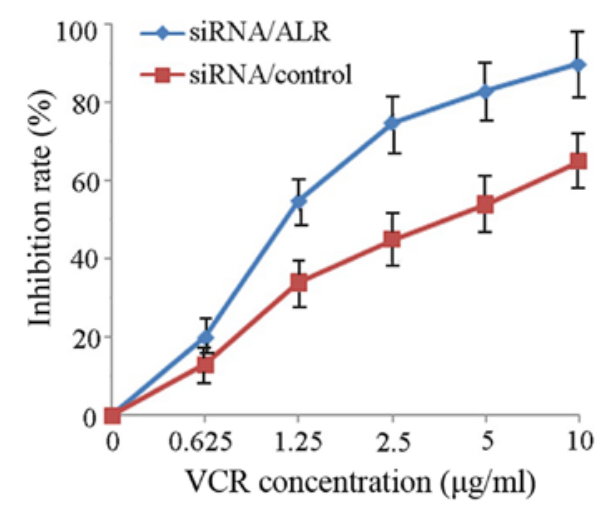

Figure 6. Suppression of ALR expression by siRNA enhances the chemosensitivity of Jurkat cells. The MTS assay revealed a dose-dependent inhibition of cell proliferation. The inhibition rates of the siRNA/ALR group were higher than that of the control siRNA group after incubation with the same VCR concentrations $(\mathrm{p}<0.05, \mathrm{n}=3)$. ALR, augmenter of liver regeneration.

previous study revealed that exogeneous ALR could protect Jurkat T leukemia cells from VCR-induced cell death, by decreasing apoptotic cells and attenuating G2/M arrest (25). The present study revealed that ALR may play an important role in Jurkat cell resistance to chemotherapeutic drugs. Cao et al found that ALR could enhance radiation sensitivity in hepatoma cells (26). Thus we further investigated whether or not the suppression of ALR expression could enhance the sensitivity of Jurkat cells to an anti-leukemic agent. In the current study, we investigated the effect of ALR silencing by siRNA on the sensitivity of Jurkat cells to VCR and explored the related mechanism.

RT-PCR, western blot analysis and confocal laser scanning microscopy revealed that ALR siRNA infection significantly reduced ALR gene mRNA and protein levels at $72 \mathrm{~h}$ post-infection in Jurkat cells. These data revealed that ALR-specific siRNA translationally suppressed the ALR mRNA. The MTS assay for cell proliferation revealed that the suppression of ALR expression markedly restrained the proliferation of the Jurkat cells, proving that ALR can exert a positive effect on leukemic cell growth. Most prominently, the data from the cell proliferation assay revealed that with ALR siRNA infection, the $\mathrm{IC}_{50}$ value of VCR obviously decreased, which led to a significant synergistic anti-leukemia effect. This supports the hypothesis that downregulation of ALR can increase the sensitivity of leukemia cells to VCR and possibly improve chemotherapy efficiency in vivo.

To further investigate the influence of ALR on survival of Jurkat leukemia cells in vitro, we detected the effect of downregulation of the ALR expression on cell apoptosis. These experiment findings indicated that siRNA-mediated suppression of ALR expression exerted an obvious effect on cell apoptosis. ALR siRNA pretreatment in combination with the chemotherapeutic agent VCR resulted in obvious apoptosis in Jurkat cells and in enhancement of chemotherapy sensitivity. On the contrary, cells infected with non-targeting siRNA in the control group had no alteration of the ALR gene expression level. Subsequently, cell growth and toxicity of VCR were not changed. These findings illustrated the specific impact of ALR siRNA in Jurkat cells. However, our findings are similar with other research which focused on the biological effects of ALR in a variety of cell lines $(17,18,30)$. Collectively, these results revealed that ALR plays a significant role in cell survival, proliferation and chemotherapy sensitivity of malignant cells. All of the observations above, ascertained that the presence of the multifunctional ALR protein is critical to the survival and chemotherapeutic agent resistance in Jurkat cells. Therefore, ALR gene silencing could induce cell apoptosis and sensitize leukemia cells to cytotoxic drugs.

The findings of the signaling pathway analysis revealed that targeted suppression of ALR expression could promote apoptotic signaling and lead to an increase of chemotherapeutic efficiency. Consequently, Jurkat ALR-knockdown cells exhibited more sensitivity to the chemotherapeutic drug. Enhanced cell death was mediated by a higher percentage 
of apoptotic cells, which was accompanied by decreased expressions of the pro-PARP, pro-caspase 8, pro-caspase 3 and Bcl-2.

Previous findings have demonstrated that ALR acts as a regulatory factor for cell cycle regulation (31-33). In the present study, we found that downregulation of ALR prevented Jurkat cell transition from the $S$ to the $G 2 / M$ phase which resulted in a decrease of the $\mathrm{G} 2 / \mathrm{M}$ ratio, while it prolonged VCR-induced G2/M arrest. The targeted suppresion of the ALR expression increased the protein levels of $\operatorname{cdc} 25 \mathrm{c}$ and $\mathrm{cdc} 2$, inhibited the dissociation of cyclin B1 and decreased G2/M ratio. Finally, it led to prevention of cell mitosis and induced Jurkat cell apoptosis. Treatment with siRNA/ALR and VCR significantly downregulated the expression of $\operatorname{cdc} 25 \mathrm{c}$ and $\operatorname{cdc} 2$, promoted dissociation of cyclin B1, resulted in prolonged $\mathrm{G} 2 / \mathrm{M}$ arrest and enhanced apoptosis. The evidence revealed that ALR knockdown may exert a bidirectional regulatory effect on Jurkat cell cycle progression. However, more research is needed to identify the roles of ALR in the regulation of leukemia cell cycle and apoptosis.

In conclusion, our findings ascertained that ALR plays important roles in both cell growth and drug susceptibility of Jurkat cells in vitro. Targeted inhibition of the ALR expression by siRNA triggered cell apoptosis and enhanced sensitivity of leukemic cells to VCR in a synergistic manner. Our study focused on the capability of ALR siRNA to sensitize the leukemia cells to chemotherapeutic agent and decrease the occurrence of anti-leukemia drug resistance. Therefore, siRNA silencing of ALR gene expression may offer a new strategy for the treatment of drug-resistant T-ALL.

\section{Acknowledgements}

This study was supported by the Medical Research Foundation of Chongqing Health Bureau (no. 2011-1-051), and partly by the Natural Science Foundation Project of CQ CSTC (cstc2017 jcyjAX0239).

\section{References}

1. Pieters R and Carroll WL: Biology and treatment of acute lymphoblastic leukemia. Hematol Oncol Clin North Am 24: 1-18, 2010.

2. Marks DI, Paietta EM, Moorman AV, Richards SM, Buck G, DeWald G,Ferrando A,Fielding AK, Goldstone AH, Ketterling RP, et al: T-cell acute lymphoblastic leukemia in adults: Clinical features, immunophenotype, cytogenetics, and outcome from the large randomized prospective trial (UKALL XII/ECOG 2993). Blood 114: 5136-5145, 2009.

3. Gianfelici V, Chiaretti S, Demeyer S, Di Giacomo F, Messina M, La Starza R, Peragine N, Paoloni F, Geerdens E, Pierini V, et al: RNA sequencing unravels the genetics of refractory/relapsed T-cell acute lymphoblastic leukemia. Prognostic and therapeutic implications. Haematologica 101: 941-950, 2016.

4. Ko RH, Ji L, Barnette P, Bostrom B, Hutchinson R, Raetz E, Seibel NL, Twist CJ, Eckroth E, Sposto R, et al: Outcome of patients treated for relapsed or refractory acute lymphoblastic leukemia: A Therapeutic Advances in Childhood Leukemia Consortium study. J Clin Oncol 28: 648-654, 2010.

5. Paszel-Jaworska A, Rubiś B, Bednarczyk-Cwynar B, Zaprutko L and Rybczyńska M: Proapoptotic activity and ABCC1-related multidrug resistance reduction ability of semisynthetic oleanolic acid derivatives DIOXOL and HIMOXOL in human acute promyelocytic leukemia cells. Chem Biol Interact 242: 1-12, 2015.
6. Soverini S, De Benedittis C, Papayannidis C, Paolini S, Venturi C, Iacobucci I, Luppi M, Bresciani P, Salvucci M, Russo D, et al: Drug resistance and BCR-ABL kinase domain mutations in Philadelphia chromosome-positive acute lymphoblastic leukemia from the imatinib to the second-generation tyrosine kinase inhibitor era: The main changes are in the type of mutations, but not in the frequency of mutation involvement. Cancer 120: 1002-1009, 2014

7. Kiraz Y, Adan A, Kartal Yandim M and Baran Y: Major apoptotic mechanisms and genes involved in apoptosis. Tumour Biol 37: 8471-8486, 2016.

8. Pistritto G, Trisciuoglio D, Ceci C, Garufi A and D'Orazi G: Apoptosis as anticancer mechanism: Function and dysfunction of its modulators and targeted therapeutic strategies. Aging (Albany NY) 8: 603-619, 2016.

9. Fodale V, Pierobon M, Liotta L and Petricoin E: Mechanism of cell adaptation: When and how do cancer cells develop chemoresistance? Cancer J 17: 89-95, 2011.

10. Zhang S, Li G, Ma X, Wang Y, Liu G, Feng L, Zhao Y, Zhang G, Wu Y, Ye X, et al: Norcantharidin enhances ABT-737-induced apoptosis in hepatocellular carcinoma cells by transcriptional repression of Mcl-1. Cell Signal 24: 1803-1809, 2012.

11. Li G, Chang H, Zhai YP and Xu W: Targeted silencing of inhibitors of apoptosis proteins with siRNAs: A potential anticancer strategy for hepatocellular carcinoma. Asian Pac J Cancer Prev 14: 4943-4952, 2013.

12. Karami H, Baradaran B,Esfehani A, Sakhinia M and Sakhinia E: Down-regulation of Mcl-1 by small interference RNA induces apoptosis and sensitizes HL-60 leukemia cells to etoposide. Asian Pac J Cancer Prev 15: 629-635, 2014

13. High LM, Szymanska B, Wilczynska-Kalak U, Barber N, O'Brien R, Khaw SL, Vikstrom IB, Roberts AW and Lock RB: The Bcl-2 homology domain 3 mimetic ABT-737 targets the apoptotic machinery in acute lymphoblastic leukemia resulting in synergistic in vitro and in vivo interactions with established drugs. Mol Pharmacol 77: 483-494, 2010.

14. Akagi H, Higuchi H, Sumimoto H, Igarashi T, Kabashima A, Mizuguchi H, Izumiya M, Sakai G, Adachi M, Funakoshi S, et al: Suppression of myeloid cell leukemia-1 (Mcl-1) enhances chemotherapy-associated apoptosis in gastric cancer cells. Gastric cancer 16: 100-110, 2013.

15. Lisowsky T, Lee JE, Polimeno L, Francavilla A and Hofhaus G: Mammalian augmenter of liver regeneration protein is a sulfhydryl oxidase. Dig Liver Dis 33: 173-180, 2001.

16. Yu HY, Xiang DR, Huang HJ, Li J and Sheng JF: Expression level of augmenter of liver regeneration in patients with hepatic failure and hepatocellular carcinoma. Hepatobiliary Pancreat Dis Int 9: 492-498, 2010.

17. Liao XH,Zhang L, Liu Q, Sun H,Peng CM and Guo H: Augmenter of liver regeneration protects kidneys from ischaemia/reperfusion injury in rats. Nephrol Dial Transplant 25: 2921-2929, 2010.

18. Polimeno L, Pesetti B, De Santis F, Resta L, Rossi R, De Palma A, Girardi B, Amoruso A and Francavilla A: Decreased expression of the augmenter of liver regeneration results in increased apoptosis and oxidative damage in human-derived glioma cells. Cell Death Dis 3: e289, 2012.

19. Polimeno L, Pesetti B, Giorgio F, Moretti B, Resta L, Rossi R, Annoscia E, Patella V, Notarnicola A, Mallamaci R, et al: Expression and localization of augmenter of liver regeneration in human muscle tissue. Int J Exp Pathol 90: 423-430, 2009.

20. Yan R, Zhang L, Xia N, Liu Q, Sun H and Guo H: Knockdown of augmenter of liver regeneration in HK-2 cells inhibits inflammation response via the mitogen-activated protein kinase signaling pathway. Inflamm Res 64: 453-462, 2015.

21. Wang N, Sun H, Shen Y, Li XF, Pan T, Liu GL and Liu Q: Augmenter of liver regeneration inhibits apoptosis of activated human peripheral blood lymphocytes in vitro. Immunopharmacol Immunotoxicol 35: 257-263, 2013.

22. Han LH, Dong LY, Yu H, Sun GY, Wu Y, Gao J, Thasler W and An W: Deceleration of liver regeneration by knockdown of augmenter of liver regeneration gene is associated with impairment of mitochondrial DNA synthesis in mice. Am J Physiol Gastrointest Liver Physiol 309: G112-G122, 2015.

23. Kumar S, Wang J, Rani R and Gandhi CR: Hepatic deficiency of augmenter of liver regeneration exacerbates alcohol-induced liver injury and promotes fibrosis in mice. PLoS One 11: e0147864, 2016.

24. Mu M, Zhang Z, Cheng Y, Liu G, Chen X, Wu X, Zhuang C, Liu B, Kong X and You S: Augmenter of liver regeneration (ALR) restrains concanavalin A-induced hepatitis in mice. Int Immunopharmacol 35: 280-286, 2016. 
25. Shen Y, Liu Q, Sun H, Li X, Wang N and Guo H: Protective effect of augmenter of liver regeneration on vincristine-induced cell death in Jurkat T leukemia cells. Int Immunopharmacol 17: 162-167, 2013

26. Cao Y, Fu YL, Yu M, Yue PB, Ge CH, Xu WX, Zhan YQ, Li CY, Li W and Wang XH: Human augmenter of liver regeneration is important for hepatoma cell viability and resistance to radiation-induced oxidative stress. Free Radic Biol Med 47: 1057-1066, 2009.

27. Li Y, Farooq M, Sheng D, Chandramouli C, Lan T, Mahajan NK, Kini RM, Hong Y, Lisowsky T and Ge R: Augmenter of liver regeneration (alr) promotes liver outgrowth during zebrafish hepatogenesis. PLoS One 7: e30835, 2012.

28. Hagiya M, Francavilla A, Polimeno L, Ihara I, Sakai H, Seki T, Shimonishi M, Porter KA and Starzl TE: Cloning and sequence analysis of the rat augmenter of liver regeneration (ALR) gene: Expression of biologically active recombinant ALR and demonstration of tissue distribution. Proc Natl Acad Sci USA 91: 8142-8146, 1994

29. Todd LR, Damin MN, Gomathinayagam R, Horn SR, Means AR and Sankar U: Growth factor erv1-like modulates Drp1 to preserve mitochondrial dynamics and function in mouse embryonic stem cells. Mol Biol Cell 21: 1225-1236, 2010.
30. Polimeno L, Pesetti B, Lisowsky T, Iannone F, Resta L, Giorgio F, Mallamaci R, Buttiglione M, Santovito D, Vitiello F, et al: Protective effect of augmenter of liver regeneration on hydrogen peroxide-induced apoptosis in SH-SY5Y human neuroblastoma cells. Free Radic Res 43: 865-875, 2009.

31. Li Y, Wei K, Lu C, Li Y, Li M, Xing G, Wei H, Wang Q, Chen J, Wu C, et al: Identification of hepatopoietin dimerization, its interacting regions and alternative splicing of its transcription. Eur J Biochem 269: 3888-3893, 2002.

32. Giorda R, Hagiya M, Seki T, Shimonishi M, Sakai H, Michaelson J, Francavilla A, Starzl TE and Trucco M: Analysis of the structure and expression of the augmenter of liver regeneration (ALR) gene. Mol Med 2: 97-108, 1996.

33. Lisowsky T: ERV1 is involved in the cell-division cycle and the maintenance of mitochondrial genomes in Saccharomyces cerevisiae. Curr Genet 26: 15-20, 1994. 